\title{
Area Classification and Types of Protection for Explosive Atmospheres: A Review
}

\author{
Bhagirath Ahirwal $^{\star 1}$, A. K. Singh ${ }^{2}$, R. K. Vishwakarma ${ }^{3}$ \\ Scientist, Flame \& Explosion Lab., CSIR-Central Institute of Mining \& Fuel Research, \\ Barwa Road, Dhanbad, (JH)-826015, India \\ Phone: +91-326-2296025, +91-326-2296003, Fax: +91-326-2296019 \\ *Corresponding author, e-mail: ahirwalcmri@yahoo.co.uk', rkvcmri@yahoo.co.in ${ }^{2}$, \\ cmri_arvind@yahoo.co.in ${ }^{3}$
}

\begin{abstract}
Ex (Explosionproof) equipment is vital for use in explosive atmospheres. The knowledge of basic of area classification, zone, temperature class, types of protection and source of ignition is mandatory for testing, manufacturing, use, installation, inspection and maintenance of Ex equipment. The paper describes the area classification, types of protection and equipment protection level for hazardous areas.
\end{abstract}

Keywords: area classification, types of protection, zone

Copyright $(2015$ Institute of Advanced Engineering and Science. All rights reserved.

\section{Introduction}

Over the years, other means of protection of greater and lesser integrity were devised. Concurrently, the need to define the areas where this apparatus could be used was broadened from a simple two zone system with a "dangerous" and a "safe" area to the present "three zone" system. The three zone system in fact implies a fourth zone designated as non-hazardous. From the very beginning it was realized that the degree of hazard could be variable and this ultimately led to the concept of area classification and the development of design techniques to ensure that electrical equipment would operate safely in specified hazardous area. The earliest form of protection for electrical apparatus was the flameproof enclosure first developed in the United Kingdom for use in coalmines and later extended to include chemical and petrochemical industries. The coal and oil mining, petroleum and fertilizer industries are the core sector of a country's economy [1-5].

\section{Explosive Atmospheres}

The flammable substances mix with the surrounding air in the proportion ratio and create an atmosphere which is called explosive atmospheres. The ignition of flammable gases, vapour or dust in the presence of oxygen contained in the surrounding air may lead to a rapid physical or chemical reaction accompanied by an increase in temperature and pressure, subject to fulfillment of certain requirements. The output of this reaction is called the explosion. Explosion is an exothermic reaction in explosion mixture or in explosive atmosphere. In order to create an explosion, three elements are needed (i) Presence of flammable substance (ii) Arc / Sparks or heated surface temperature/source of ignition energy, and (iii) Oxidizer (oxygen in the air). These elements are generally present in the triangle for explosion.

The first two elements must be present in sufficient quantities to form a potentially explosive atmosphere. These oxidation reactions normally involve the release of heat and pressure, which are the major criteria for an explosion. Liquefied petroleum gas (LPG) stove provides the simplest example of a small explosion. When the knob is operated, jet within the burner releases a small amount of flammable gas, which mixes with the immediately surrounding atmospheric air and comes out of the burner as a flammable gas air mixture. Spark from the gas lighter ignites and then it burns. The quantity of released gas being controlled and the flame is limited to immediate vicinity of the burner of the stove. However, when there is no control either on quantity, rate of release of flammable media or source of ignition, then this may 
lead to an explosion instead of a controlled flame. The quantity and rate of flammable media, even with the best design of Ex equipment and operational precautions can be minimized but cannot be eliminated and hence lead to a flammable atmosphere in the industry.

\section{Area Classification}

The area classification of explosive atmospheres is a method of analyzing and classifying the environment where explosive gas atmospheres may occur. The area classification depends on many factors like frequency and duration of release, the release rate, concentration, velocity, ventilation, geometry of the source of release, volatility of flammable liquid, liquid temperature, lower explosive limit, upper explosive limit, relative density of the gas or vapour, climatic condition and topography etc.

\subsection{Gas Group}

The electrical apparatus for a potentially explosive atmosphere are divided into two groups as per IS/IEC 60079-0 standard [1]:

1) Group I electrical apparatus - for mines susceptible to fire damp.

2) Group II electrical apparatus - for gases with potentially explosive atmosphere other than mines susceptible to fire damp.

The gas group II is further sub divided into gas group IIA, IIB and IIC. The gas group IIC is more stringent than gas group IIA/IIB. Each gas group has its representative gas which is shown in Table 1.

Table 1. Representative gas for gas group

\begin{tabular}{cc}
\hline Gas group & Representative gas \\
\hline I & Methane \\
IIA & Propane \\
IIB & Ethylene \\
IIC & Hydrogen \& Acetylene \\
\hline
\end{tabular}

\subsection{Zone Classification}

The boundary of a particular zone of hazardous area is mainly determined by both chemical and physical parameters, such as the release rate of gas or vapor and duration of release in normal condition [2]. There are three types of zones namely zone 0 , zone 1 and zone 2 can be present in any explosive atmosphere as per IS 5572:2009 and IEC 60079-10 [3, 4].

\subsection{Temerature Classification}

Design of any explosion-proof protected equipment is tested to determine its temperature class based on maximum temperature attained in continuous normal working condition. The temperature class identifies the hottest temperature on the equipment which can be on either the inside or the outside of the equipment depending on the protection concept. The selection of equipment is such that, the temperature class must be lower than the minimum ignition of explosive mixture in that area [5]. The European Norms (EN), International Electrotechnical Cmmission (IEC), Indian Standard (IS) and many more standards have formulated six classes of temperature from $\mathrm{T} 1$ to $\mathrm{T} 6$ for uniformity and standardization. These six temperature classes from $\mathrm{T} 1\left(450^{\circ} \mathrm{C}\right), \mathrm{T} 2\left(300^{\circ} \mathrm{C}\right), \mathrm{T} 3\left(200^{\circ} \mathrm{C}\right), \mathrm{T} 4\left(135^{\circ} \mathrm{C}\right), \mathrm{T} 5\left(100^{\circ} \mathrm{C}\right)$ and T6 $\left(85^{\circ} \mathrm{C}\right)$ as per IS/IEC 60079-0, EN 60079-0 and IEC 60079-0 standards [6, 7]. As the temperature class increases, the temperature decreases.

\section{Source of Ignition in the Hazardous Area}

There are two kinds of ignition sources for hazardous areas, i.e. electrical and nonelectrical as given in Table 2. These predominantly ignition sources can be produced from the normal equipment $[8,9]$. 


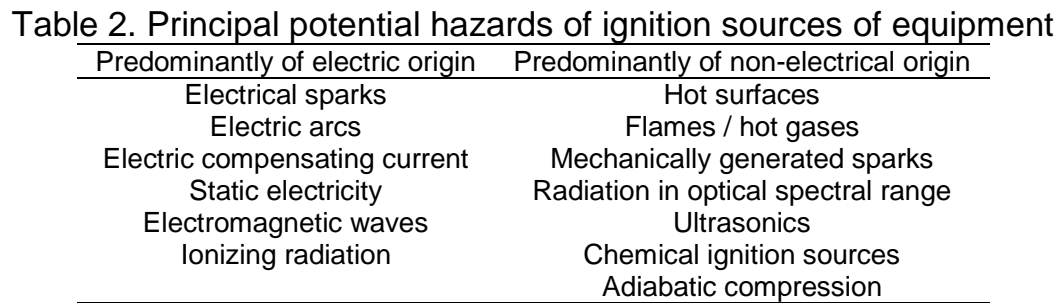

\section{Type of Protections for Hazardous Area}

It is necessary to prevent the source of ignition in the potentially explosive atmosphere to avoid any explosion. There are generally nine types of protection are being used to design Ex equipment for explosive atmospheres as per IS/IEC/EN standards. And these techniques are known as types or methods of protection [10] as given below:

\subsection{Flameproof Protection (Ex d)}

IS/IEC 60079-1 defines flameproof as "Enclosure in which the parts which can ignite an explosive gas atmosphere are placed and which can withstand the pressure developed during an internal explosion of an explosive mixture, and which prevents the transmission of the explosion to the explosive gas atmosphere surrounding the enclosure". The design of an enclosure should be such that the flame should not be transmitted to the outer atmosphere. Mechanical integrity of the enclosure should be such that it does not get damaged during the non-flame transmission test, reference pressure test and over pressure test. The safety of the flameproof equipment depends on the mainly flamepath and gap/diametrical clearance/pitch value as given in IS/IEC 60079-1 or EN 60079-1standards and they depend on the volume of the enclosure and gas group [11, 12].

\subsection{Intrinsic Safety (Ex i)}

An intrinsically safe circuit may be defined as a circuit in which any spark produced under normal conditions or specified fault conditions is incapable of causing ignition in a prescribed gas mixture. Intrinsic safety is a technique in which energy is limited within the circuit of the apparatus. Intrinsically safe apparatus does not require any special form of enclosure but certain safeguards are required as per IS/IEC 60079-11 and EN 60079-11 [13, 14].

There are three categories of intrinsically safe apparatus - ia, ib and ic. The categories differ in two main aspects - firstly, in the number of specified fault and secondly, in the values of safety factor. The safety factor is the amount of load, above the normal operating rating of component that a device can handle without failure.

\subsection{Increased Safety (Ex e)}

The protection concept (type of protection) of increased safety is intended for use in Zone 1 and less hazardous areas. It is a German development (erhohtesichereit, which means increased safety, which explains the use of 'e' as its concept symbol). Increased safety did not figure significantly in UK before 1970 and only became important because of the effect on UK attitudes produced by the increasing importance of the European dimension emerging at the time of the European Free Trade Association (EFTA), of which the UK was a member prior to its entry into the European Union (EU). It gained further importance in UK with the UK's entry into the EU itself.

The definition of Increased Safety as per IS/IEC 60079-7: 2006 is "The type of protection applied to electrical apparatus in which additional measures are applied so as to give increased security against the possibility of excessive temperatures and of the occurrence of arcs and sparks in normal service or under specified abnormal conditions" [15].

\subsection{Non-Sparking Safety (Ex $n$ )}

The basic feature of the non-sparking protection is that it is constructed and maintained so that it cannot produce incendive spark in normal operation. The non-sparking protection is 
called non-incendive type of protection in the USA. Enclosure for apparatus must be protected against impact, entry of dirt and moisture. The electrical connection must be reliable. Adequate separation is required between the live part and the earth. In these types of equipments, only such components or assemblies are used, which are incapable of producing sparks, thus eliminating the source of ignition as specified in the IS/IEC 60079-15 [16].

\subsection{Oil Immeresed Safety (Ex o)}

In this protection, the sparking contacts are protected from flammable gases by being immersed in oil to a depth decided on the basis of a test carried out by a testing authority. The oil immersed protection is specified in the IS/IEC 60079-6 [17]. The general constructional requirements for this protection may be as follows:

1) Oil should have high dielectric strength and good thermal conductivity.

2) They should have negative aspect of flammability and forming of carbon particle during arc quenching.

3) Enclosure must be protected against impact, entry of dirt and moisture.

4) Creepage distance and clearance must be maintained between connecting terminals as per relevant code.

\subsection{Pressurised (Ex p)}

It is the protection technique which is best suited for large enclosures. Pressure within the enclosure is kept $0.5 \mathrm{mbar}$ above the atmospheric pressure so that explosive gas from the external environment cannot ingress into the pressurized enclosure. The supply of pressurized gas must be sufficient to compensate any leakage by enclosure. Safety devices such as time delay relay, alarm and flow meter shall be provided to ensure that the pressurized apparatus cannot be energized until it has been purged by a quantity of protective gas sufficient to reduce the concentration of any flammable gas in the enclosure. An automatic device shall be provided to switch off the enclosed apparatus when the over pressure falls below the minimum prescribed value. There are three types of pressurization methods for pressurized protection usually used in the hazardous areas, namely Px, Py and Pz as defined in the IS/IEC 60079-2 standard $[18,19]$.

\subsection{Powder Filling (Ex q)}

This type of protection was developed in France and is similar to the type of protection Ex ' $o$ '. But in this form of protection, the incendive parts are immersed in quartz or other similar powder. The minimum safe filling height has been found to be 15 percent greater than the height in which ignition may occur. Quartz grade sand is a very good media to suppress arc / sparks and it is used in sand filled equipments to prevent explosion hazard by isolating spark from surrounding hazardous gases as per IS/IEC 60079-5 standard [20].

\subsection{Encapsulation (Ex m)}

The encapsulation protection is defined in IS/IEC 60079-18 as " a type of protection whereby parts that are capable of igniting an explosive atmosphere by either sparking or heating are enclosed in a compound in such a way that the explosive atmosphere cannot be ignited under operating or installation conditions". It is also known as potting. The principle of this form of protection is that the apparatus to be protected by enclosing in a submerged suitable substance in liquid state. The substance is then allowed to cool and form a solid block/compound. The apparatus may then be enclosed within a rigid casing or it may not be necessary. Encapsulation is very useful in eliminating entry of explosive atmosphere within an apparatus. But this type of protection cannot be used where the apparatus has moving parts. Ex $m$ type of protection is dependent on the mechanical and physical properties of the compound as per requirement of IS/IEC 60079-18 [21].

\subsection{Special Protection (Ex s)}

The special protection does not have any standard. The apparatus is designed in such a way that it cannot become a source of ignition in the explosive atmosphere. The testing laboratory should ensure that the equipment is not incendive in a hazardous area. 


\section{Discussion}

The Ex equipment are designed, certified, approved and used for hazardous area. These Ex equipment have various rules and regulation which depends on the country. The concept of design is more or less same globally but some differences are there. These differences are basically subject to approval, design and use. The Indian standards are same as IEC standards for design, testing and use in hazardous area. The approval process for granting the permission for safe use of these equipment in hzardous area is diffrent. ATEX certification is mandatory in the Europeon Union but not in India. USA and Canada and its continents are having their own standards and approval policy which are not identical to ATEX scheme.

Now, Ex equipment are being imported and exported for the particular purposes to install in the explosive atomspheres by manufacturers globally. So it is very importnat to check all the basic requiremnts of end user, certification and approval policeies of the concered countries.

\section{Conclusion}

The hazardous area is very vast and important subject. The knowledge of basic concept is mandatory to the concerned who is involved in operation, testing and manufacturing of Ex equipment. The use of Ex equipment is dependent on the type of protection and area classification. If the Ex equipment are choosen properly, accident form explosion can be avoided in the hazardous area where innocent workers are working.

\section{References}

[1] Bureau of Indian Standard IS/IEC 60079-0. Electrical apparatus for explosive gas atmosphereGeneral requirement. India. 2004.

[2] Rangel E, Fanara JR. Classified areas extents. Proceedings of $5^{\text {th }}$ Petrobras Electrical Engineering Seminar. Anais, France. 1999; 104-118.

[3] Bureau of Indian Standard IS 5572. Classification of hazardous areas (other than mines) having flammable gases and vapours for electrical installation. India. 2009.

[4] International Electrotechnical Commission IEC 60079-10. Electrical apparatus for explosive gas atmospheres- Classification of hazardous areas. Geneva. 2002.

[5] Ahirwal B, Singh AK, Vishwakarma RK, Sinha A. Effect of temperature on explosion-proof equipment in hazardous area. Proceedings of $9^{\text {th }}$ International Mine Ventilation Congress. 2009: 199-203.

[6] International Electrotechnical Commission IEC 60079-0. Electrical apparatus for explosive gas atmosphere- General requirement. Geneva. 2004.

[7] CENELEC, European Standardization Organization EN 60079-0. Electrical apparatus for explosive gas atmospheres - Part 0: General requirements. Belgium. 2006.

[8] Agrawal N. Introduction to hazardous area and area classification. First International Seminar DTEX2009. 2009: 167-173.

[9] Bianco L, Feudale F, Razza F, Sica M, Contin A, Rabach G. High voltage induction motors for use in hazardous areas: Evolution of legal aspects and technical investigations related to safety problems. Proceedings of $5^{\text {th }}$ IEE Conference on Electrical Safety in Hazardous Environments. London. 1994: 84-92.

[10] Owler A. Which 'type of protection' [electrical equipment safety]. Proceedings of Fourth IEEE International Conference on Electrical Safety in Hazardous Area. London. 1988: 131-135.

[11] Bureau of Indian Standard IS/IEC 60079-1. Electrical apparatus for explosive gas atmospheres: Part 1 -Flameproof enclosure "d". India. 2007.

[12] CENELEC, European Standardization Organization EN 60079-1. Explosive atmospheres - Part 1: Equipment protection by flameproof enclosures "d". Belgium. 2007.

[13] CENELEC, European Standardization Organization EN 60079-11. Explosive atmospheres - Part 11: Equipment protection by intrinsic safety "i". Belgium. 2007.

[14] Bureau of Indian Standard IS/IEC 60079-11. Electrical apparatus for explosive gas atmospheres: Part 11 - Intrinsic Safety "i". India. 2006.

[15] Bureau of Indian Standard IS/IEC 60079-7. Electrical apparatus for explosive gas atmospheres: Part 7 -Increased Safety "e". India. 2006.

[16] Bureau of Indian Standard IS/IEC 60079-15. Electrical apparatus for explosive gas atmospheres: Part 15 -Construction, test and marking of type of protection " $n$ " electrical apparatus. India. 2005.

[17] Bureau of Indian Standard IS/IEC 60079-6. Electrical apparatus for explosive gas atmospheres: Part 6 - Oil immersion "o". India. 2007.

[18] Bureau of Indian Standard IS/IEC 60079-2. Electrical apparatus for explosive gas atmospheres: Part 2

TELKOMNIKA Vol. 16, No. 2, November 2015 : $238-243$ 
-Electrical apparatus, type of protection "p". India. 2007.

[19] Ahirwal B, Singh AK, Vishwakarma RK and Sinha A. Study of minimum overpressure location on high tension purged and pressurized protected Ex ' $p$ ' motor for explosive atmospheres. Elsevier International Journal of Electrical Power and Energy Systems. 2012; 41: 120-123.

[20] Bureau of Indian Standard IS/IEC 60079-5. Electrical apparatus for explosive gas atmospheres: Part 5 -Powder filling " $q$ ". India. 2004.

[21] Bureau of Indian Standard IS/IEC 60079-18. Electrical apparatus for explosive gas atmospheres: Part 18 - Construction, test and marking of type of protection " $m$ " electrical apparatus. India. 2004. 